\title{
Between "worlds apart": Situating student work between the academic classroom and workplace
}

Maria Wilson, Clara John, Natasha Artemeva, Elena Aminkova, Jennifer Ballantyne, Meagan McGiffin, and Rosana Hilbig

Carleton University

Cet article fait état d'un projet longitudinal qui tente de situer l'écriture scolaire dans l'espace séparant le monde universitaire de celui du travail. Ce projet a été réalisé par plusieurs groupes d'étudiants d'années différentes suivant le même cours. Les auteurs estiment que l'engagement fait par l'étudiant à partager son savoir avec la communauté linguistique d'un milieu de travail donné lui permet d'observer le contexte de ce milieu de l'intérieur, d'y adapter ses connaissances intellectuelles et de mettre en pratique ces connaissances de façon adéquate. Ce type de projets longitudinaux donnent aux étudiants loccasion de dialoguer fructueusement avec les générations qui les ont précédés et de se fonder sur leurs travaux. Les projets conçus pour assurer le partage des connaissances et la collaboration devraient aider les étudiants d̀ mieux comprendre les subtilités de la communication en milieu de travail et à découvrir des liens entre connaissances universitaires et pratique du travail.

This article reports on a longitudinal project that attempts to situate student writing in the space between the worlds of academia and workplace. The project was conducted by several groups of students who took the same course in different years. The authors argue that student engagement in knowledge sharing with a workplace discourse community allows students to experience the workplace context from within, adapt their academic knowledge to it, and apply this knowledge appropriately. Such longitudinal projects provide students with an opportunity to enter into a productive dialogue with previous generations of students and build upon their work. Projects designed to ensure knowledge sharing and collaboration promise to help students better understand the intricacies of workplace communication and find connections between academic knowledge and workplace practice.

Recent research into academic and workplace acting and writing (e.g., Dias, Freedman, Medway \& Paré, 1999; Dias \& Paré, 2000) convincingly demonstrates that there are profound differences between writing that occurs in the academic classroom and 
writing that occurs in the workplace. This conclusion is succinctly summarized in the title of the book Worlds Apart: Acting and Writing in Academic and Workplace Contexts that Dias et al. coauthored (1999): the classroom and workplace are "worlds apart." One of the main claims that Dias et al. make is that, often, academic classroom writing lacks the complexity and richness of workplace communication. They suggest a way in which academic courses may help students better understand and respond to the complex contexts of workplace communication. This task could be accomplished

through constituting the class as a working group with some degree of complexity, continuity, and interdependency of joint activity. Such arrangements will go some way toward realizing the far richer communicative relations that contextualize writing in the workplace. (p. 235)

Hunt (2001) takes the discussion further by suggesting that researchers and educators should explore the space between the "worlds apart" in order to investigate how the richness of workplace communication "might be brought into higher education contexts"(n.p.). This article reports on a project that attempts to do just that by situating graduate course work in the space between the worlds of academia and workplace. It presents and discusses the results of a longitudinal workplace-based project, in which graduate students explored the roots of the problems that a local group of physiotherapists experienced when using ineffective promotional materials.

The project presented in this article brought together workplace practitioners and graduate students and allowed them to engage in knowledge sharing situated between the two worlds, thus giving the students an opportunity to use their academic knowledge to assist the practitioners in solving a communication problem. The project discussed in this article was designed to promote collaboration between the students, practitioners, and course professor.

As research into academic and workplace communication has shown, one of the main characteristics of workplace writing is its multiple authorship, while sole authorship continues to be one of the most typical features of student writing in academia (e.g., Dias et al., 1999; Dias \& Paré, 200o; Ede \& Lunsford, 1992; Winsor, 1996). This article, co-authored by six graduate students who took Academic and Workplace Genres in 2002 and 2003 and the course professor, includes two main sections reporting on the research and implementation phases of the project. In Phase One of the project - research and analysis of the promotional materials conducted in 2002 - four students collaborated on the study of the causes of promotional material ineffectiveness. In Phase Two of the project - the implementation of Phase One recommendations and design of new promotional materials - a team of two students enrolled in 
the same course a year later, and in 2003 developed a new set of promotional materials for the physiotherapists.

In this article, we present a brief background of the project, a review of the theoretical framework used, the textual and user-based analyses of the persuasive effectiveness of the promotional materials, and a description of the design of a new set of Feldenkrais Method promotional materials. We conclude by discussing the project's implications for the academic classroom.

\section{The Need for the Project: The Feldenkrais Method Promotional Materials}

The project discussed in this article grew out of local Feldenkrais Method practitioners' search for an explanation for an apparent failure of the promotional materials they were using to attract new clients to the Feldenkrais Method workshops and classes. The Feldenkrais Method (subsequently referred to as the F.M. or the Method) is a system of gentle exercises that explores new patterns of movement and generates increased ease and pleasure of human movement by expanding self-awareness (Feldenkrais ${ }^{\circledR}$ Educational Foundation of North America, n.d.; Feldenkrais resources, n.d.; New Zealand Feldenkrais Guild Inc., n.d.). The Method stimulates development and encourages people of all ages and abilities to continue learning more efficient and easier ways of moving. According to Nancy Parker, an Ottawa F.M. practitioner, "the Feldenkrais Method provides a means whereby we can actualize our own selfimage without being corrected or explicitly directed into learning"; that is, the Method helps us "to start moving with "mindful spontaneity" (personal communication, January 5,2004$)$.

Local F.M. practitioners approached the instructor of an Academic and Workplace Genres course and asked her to assist them in finding causes of the apparent failure of the F.M. promotional materials to attract the desired number of new clients to their workshops and classes. On the basis of the F.M. practitioners' request, the course instructor designed a project for her graduate students that would allow the students to apply their theoretical knowledge of genres in the context of F.M. practice. In 2002, two groups of graduate students started working on Phase One of the project, which included two sub-studies conducted concurrently: a rhetorical analysis of the persuasive effectiveness of the existing promotional materials and usability testing of the materials with real audiences, that is, current and potential clients of the Method. A year later, another group of students enrolled in the same course continued to work on the implementation phase of the project (Phase Two) and designed a new set of promotional materials following Phase One recommendations. 
In the project described in this article, we applied the concepts developed within Rhetorical Genre Studies ${ }^{2}$ (RGS) to analyze the persuasive effectiveness of the promotional materials produced by the Feldenkrais ${ }^{\circledR}$ Education Foundation of North America (FEFNA) and distributed by the Feldenkrais ${ }^{\circledR}$ Guild of North America (FGNA) (subsequently referred to as the Guild). ${ }^{3}$ The objective of Phase One of the project was to use the RGS framework to study the context for which the promotional materials were designed and analyze several sample texts that represented a few genres of the F.M. promotional literature. We studied the reader/writer relationships that were established through the promotional materials in order to determine what rhetorical patterns in the promotional materials prevented (or enabled) them to disseminate the F.M. community's knowledge beyond its borders. Our intention was to provide the F.M. practitioners with recommendations that would ensure an overall improvement of the materials, and possibly serve as a foundation for the design of a new, more effective set of promotional materials.

\section{Theoretical Background}

Rhetorical Genres Studies provides the main theoretical framework for the project. Recent RGS research (e.g., Coe, Lingard, \& Teslenko, 2002; Dias et al., 1999; Dias \& Paré, 2000; Freedman, 2003a, 2003b; Freedman \& Medway, 1994a, 1994b) has reconceptualized interactions between texts and their social contexts: texts are no longer viewed as the sole form and substance of different genres - they are analyzed as rhetorical actions, both embedded in and forming various social situations (Artemeva, 2004; Bawarshi, 2000; Miller 1984/1994; Schryer, 2000, 2002). RGS permits us to examine social motives and needs that underlie the creation of any text and to determine whether writers and readers are able to establish relationships through the texts (i.e. to communicate).

The complexity of workplace relationships - in our case, the relationships between the writers of promotional materials and the users of the materials - presents a specific rhetorical challenge, as it involves different needs and purposes, various types of texts, multiple writers, and multiple readers. For almost twenty years, workplace writing has attracted the attention of composition scholars (e.g. Dias et al., 1999; Dias \& Paré, 2000; Freedman \& Medway, 1994a, 1994b; Schryer, 2000, 2002; Spilka, 1993). Their work has been based on Miller's seminal article "Genre as Social Action" (1994/1984), in which Miller further developes Bitzer's (1968) Burkean concept of rhetorical situation, wherein discourse is seen as responding to the audience, constraints, and exigence of the situation in question. In Miller's view, understanding genre in the social context "can help account for the ways we encounter, interpret, react to, and create particular texts" (p. 23). In our project, Miller's view has helped us focus on a 
particular rhetorical situation and analyze how readers - F.M. practitioners, clients, and potential clients - encounter, interpret, and react to a set of F.M. promotional materials. At the same time, the analysis of the materials has allowed us to determine whether rhetorical actions undertaken by the F.M. writers enabled them to communicate effectively with their readers.

Rhetorical situations are socially constructed and necessitated by exigencies (Miller, 1984/1994), which, through texts, regulate the interactions between readers and writers. Bitzer (1968) defines exigence as "a specific combination of persons, events, and instruments that creates a need for communication" (p. 7). According to Miller (1984/1994), exigence is a social motive, or need, that leads to a rhetorical action. Any piece of writing is not seen as abstracted from its social context, but rather is seen as a way of responding to a particular social situation. In the situation that we studied in our project, the Guild's exigence was to promote the Method and, consequently, attract new clients, help people improve their physical well being, and so meet a public need for new methods of improving health.

Genre researchers (e.g., Freadman, 1994; Schryer, 2000) reassert the equal importance of textual and nontextual responses to an utterance. For example, in the project presented in this article, we have analyzed the effects of the F.M. promotional materials on potential F.M. clients. If, after having read the promotional materials, new clients register for F.M. classes, this non-textual response to the materials - the act of registering - proves to us that the materials are effective; that is, the materials fulfill their rhetorical function if they manage to inform and consequently attract new clients.

Our analysis has been largely based on the work of Paré and Smart (1994). Paré and Smart see genre as "a broad rhetorical strategy enacted within a community in order to regularize writer/reader transactions in ways that allow for the creation of particular knowledge" (p. 146). Texts reflect and represent experience, social roles, and needs, and rely on rhetorical and linguistic resources for making meaning. The concept of genre, defined as a "distinctive profile of regularities across four dimensions: a set of texts, the composing processes involved in creating these texts, the reading practices used to interpret them, and the social roles performed by writers and readers" (p. 147), allows a researcher to explore "the full range of social action that constitutes an organization's repeated rhetorical strategies, or genres" (p. 153). In our project, we explore the persuasiveness of promotional materials that are representative of two genres, which FEFNA and the Guild employ among other genres of promotional materials to perform their social action of promoting the Method and attracting new clients. 
Deal and Kennedy (as cited in Odell \& Goswami, 1985) observe that "writers who are members of an organization (a corporation, a bureaucracy, a school, a club) may have internalized values, attitudes, knowledge and ways of acting that are shared by other members of the organization. This culture influences practically everything in the life of the organization" (p. 250). This statement, applied to our analysis of the F.M. promotional materials, demonstrates how knowledge about the Method, shared by the members of FEFNA and the Guild, is delivered outside of the F.M. community and illustrates how the F.M. promotional materials establish unequal relationships between readers and writers. Furthermore, our analysis also demonstrates how FEFNA's and the Guild's initial intentions to promote the Method and attract new clients have been diminished by inappropriate rhetorical moves used in the F.M. promotional materials.

Swales (1990) makes an important contribution to rhetorical genre theory by suggesting that genres are located within their discourse communities. According to Swales, discourse communities develop, use, and modify written genres in response to the recurrent rhetorical situations they face. Swales (1990) presents a fully developed notion of discourse community as a construct, which provides insight into the "socio-rhetorical" activities of groups. These groups communicate their norms and values and conduct their affairs through the appropriation and use of particular forms of discourse (Artemeva, 2004). Swales' notion of discourse community helps us realize why linguistics and rhetorical patterns used in the F.M. promotional materials failed to communicate the intended message to the readers located outside of the F.M. community.

In the following sections, we discuss Phases One and Two of the project that were completed in 2002 and 2003, respectively. Phase One comprises sub-studies 1 and 2 that were completed concurrently by two different groups of students: substudy 1 provides a rhetorical analysis of the persuasive effectiveness of two texts that represent two genres of the existing F.M. promotional materials. Sub-study 2, an empirical inquiry, or usability testing, based on the grounded theory approach (Glaser \& Strauss, 1967) has allowed us to gain some consumer insight into why the F.M. promotional materials failed to attract new clients to F.M. classes and workshops. For the purpose of sub-study 2, consumer insight is defined as the immediate feedback from the F.M. current and potential clients alike as it pertains to their opinions and perceptions of the Method and its promotional materials. Phase Two, completed in 2003, is dedicated to the development and design of new promotional materials on the basis of the recommendations provided in Phase One. 


\section{Methods}

This section describes the methodology used in Phases One and Two of the project.

\section{Phase One: Rhetorical Analysis and Usability Testing of the F.M. Promotional Materials}

In our attempt to find the causes of the F.M. promotional materials' failure we (a) conducted a rhetorical analysis of the persuasive effectiveness of the promotional materials (sub-study 1), and (b) interviewed individuals who had participated in the Feldenkrais Method activities and those who had never heard of the Method but could potentially benefit from it (sub-study 2).

\section{Sub-study 1: Rhetorical Analysis of Two Texts}

A sample of the F.M. promotional materials was analyzed to determine the characteristics of the writer/reader relationship in the context of the promotional campaign and to examine the reasons why the materials had not attracted enough attention and interest from potential clientele. We reviewed a selection of texts that represented several genres of the F.M. promotional materials: handouts for beginners, promotional brochures, and posters designed to attract clients to the F.M. classes, workshops, and other activities. For the rhetorical analysis, we selected typical texts that represented two genres of promotional materials: information brochures that are commonly used to attract new clients to various health improvement methods and posters that are commonly used to attract clients to a particular event. The texts representing each of these genres selected for the analysis were a) the information brochure Movement is Life: Feldenkrais Method of Somatic Education published by FEFNA (further referred to as the brochure or Figure 1, Text 1$)^{4}$ and b) the Awareness Through Movement (ATM) workshop poster Shoulder to Shoulder (further referred to as the poster or Figure 2, Text 2). ${ }^{5}$ The texts were analyzed from a rhetorical perspective that required us to immerse ourselves in the context for which the promotional materials were produced and to study this context. The study of this context was based on an analysis of an audio taped and transcribed interview with two local F.M. practitioners recorded in October 2001 when they approached the course professor with their request, several informal meetings with the F.M. practitioners, and several F.M. classes that we attended and participated in. These essential experiences allowed us a) to gain insights into the current needs and goals of the practitioners and their views of the target audience and perceived problems with the promotional materials and b) to experience the context in which the promotional materials were expected to function. 
In our analysis, we followed a set of research questions:

1. What motivated the production and distribution of the promotional materials?

2. How can we assess the persuasive effectiveness of the promotional materials?

3. What can we infer from the promotional materials about the writers' intentions and the reading practices of potential F.M. clients?

4. How do the readers approach a text? How do they navigate the text? How do they understand it? What do they do with the knowledge they construct?

\section{Sub-study 2}

Using the grounded theory approach (Glaser \& Strauss, 1967), we developed questionnaires (Appendices A and B), which were distributed to the sub-study 2 participants in order to conduct usability testing of the F.M. promotional materials on the target audience. This usability testing allowed us to obtain information on the effectiveness of the two documents that were concurrently analyzed within the framework of sub-study 1.

\section{Participants}

Our research sample consisted of four male participants - two were the current clients of the Feldenkrais Method and two were not clients of the Feldenkrais Method (further referred to as non-clients). The rationale behind the sample being comprised of all males was to eliminate the risk of gender-related interpretations of the responses obtained. The age group of the Feldenkrais client portion of our sample is 40 to 50 years and the non-client portion ranges between the ages of 20 and 30 years. The non-client portion of our sample was selected based on the nature of their occupation: both non-clients are professionals in the high-tech sector, a type of work that requires long hours spent at a computer. The targeting of a specific social/professional group, such as the non-clients, was done on the premise that this particular group would benefit from the F.M. due to the work-related musculoskeletal discomforts from which they may suffer.

Instruments and samples of promotional materials

We designed two versions of the questionnaire; one version was developed for the F.M. client group (Appendix A), and the other version for the non-client group (Appendix B). Each version of the questionnaire consisted of four questions; one of the four questions was identical across both versions, as it served as a control question so that a comparison of responses across both groupings of the sample could be possible (highlighted in both Appendices A and B). Appended to each version of the 
distributed questionnaires were promotional materials, analyzed in sub-study 1: Text 1 (Fig. 1) and Text 2 (Fig. 2). Participants were asked to comment on each of the promotional materials. All questionnaires were designed to elicit two kinds of responses from our research sample:

1. Participants' attitudes towards the F.M. - attitudes based on experience, for the clients, and attitudes based on the promotional materials, for the non-clients;

2. Participants' opinions and perceptions of the samples of the F.M. promotional materials.

The previously recorded and transcribed interview with the F.M. practitioners served as a means of comparison between the collected responses from our sample and the practitioners' views on the effectiveness of the promotional literature.

Procedures

The data collected from the three participant groups (the clients, the non-clients, and the F.M. practitioners) were coded separately to establish certain categories that served to organize all our data. We then brought the coded categories from all three groups together and attempted to trace common themes that recurred throughout all data pools. From each of the participant groups, we were able to uncover predominant themes that recurred throughout all the responses.

\section{Phase Two: Implementation of Phase One Recommendations}

In Phase Two, completed a year later, we used recommendations developed within Phase One to design a new set of the F.M. promotional materials; in other words, Phase Two can be seen as the implementation phase of the project.

In order to achieve the goal of Phase Two, that is, to design a new set of the F.M. promotional materials, we took the following three steps:

1. Research of the workplace setting: The F.M. practice

For eight weeks, we attended Awareness Through Movement (ATM) classes taught by Lisa Woolnough, a local F.M. practitioner. ATM is a group lesson in which an F.M. practitioner guides clients through a series of explorations of movements particular to the Method.

2. Information gathering: Analysis of the F.M. websites We researched F.M. websites developed in different countries (e.g., Italy, New Zealand, Australia, England, Argentina, the U.S., and Canada) in order to understand the complexities of the Method-specific communication and the different purposes of various types of texts presented on 
the websites (e.g., Australian Feldenkrais ${ }^{\circledR}$ Guild Inc., 2003; Feldenkrais Guild ${ }^{\circledR}$ of North America, n.d.; Feldenkrais resources, n. d.; New Zealand Feldenkrais ${ }^{\circledR}$ Guild Inc., n. d.). Our goal was to understand how the essence of the F.M. is communicated to different groups of readers.

3. Information gathering: Analysis of the promotional materials produced by F.M. competitors

We analyzed promotional materials produced by competitors of the Feldenkrais Method who offer comparable services, such as, for example, the Alexander Technique (e.g., Rickover \& Rickover, n. d.). The analysis of these samples of promotional materials allowed us to understand how alternative services market themselves to the public and to determine successful and unsuccessful techniques/strategies in their promotional materials.

\section{Analysis and Discussion}

\section{Phase One}

According to the F.M. practitioners, the F.M. promotional materials are created with the purpose of educating the public, making the Method widely known, demonstrating new techniques of exercise and rehabilitation, and attracting potential clients. In the preliminary interview, the F.M. practitioners indicated that the promotional materials had failed to attract a desired number of new clients. The practitioners also observed that there was a contradiction between the way the Method was described in the materials and the way it was presented in the F.M. classes. The analysis of the rhetorical effectiveness of two texts from the F.M. promotional materials conducted within Phase One of the project revealed that a rhetorical action undertaken by the F.M. promotional material writers had failed to meet the needs of the readers. Phase One recommendations suggest ways of improving the persuasive effectiveness of the promotional materials.

Sub-study 1: Rhetorical Analysis of the Promotional Materials

The promotional brochure Movement is Life: Feldenkrais Method of Somatic Education (Figure 1, Text 1) is a blue and white double-sided six-panel brochure. The text of the brochure provides general information about the history and essence of the Method and the F.M. activities.

The workshop poster Shoulder to Shoulder (Figure 2, Text 2) is a typed one-sided poster printed on a background of blue clouds, which informs current and potential clients of an F.M. workshop. 


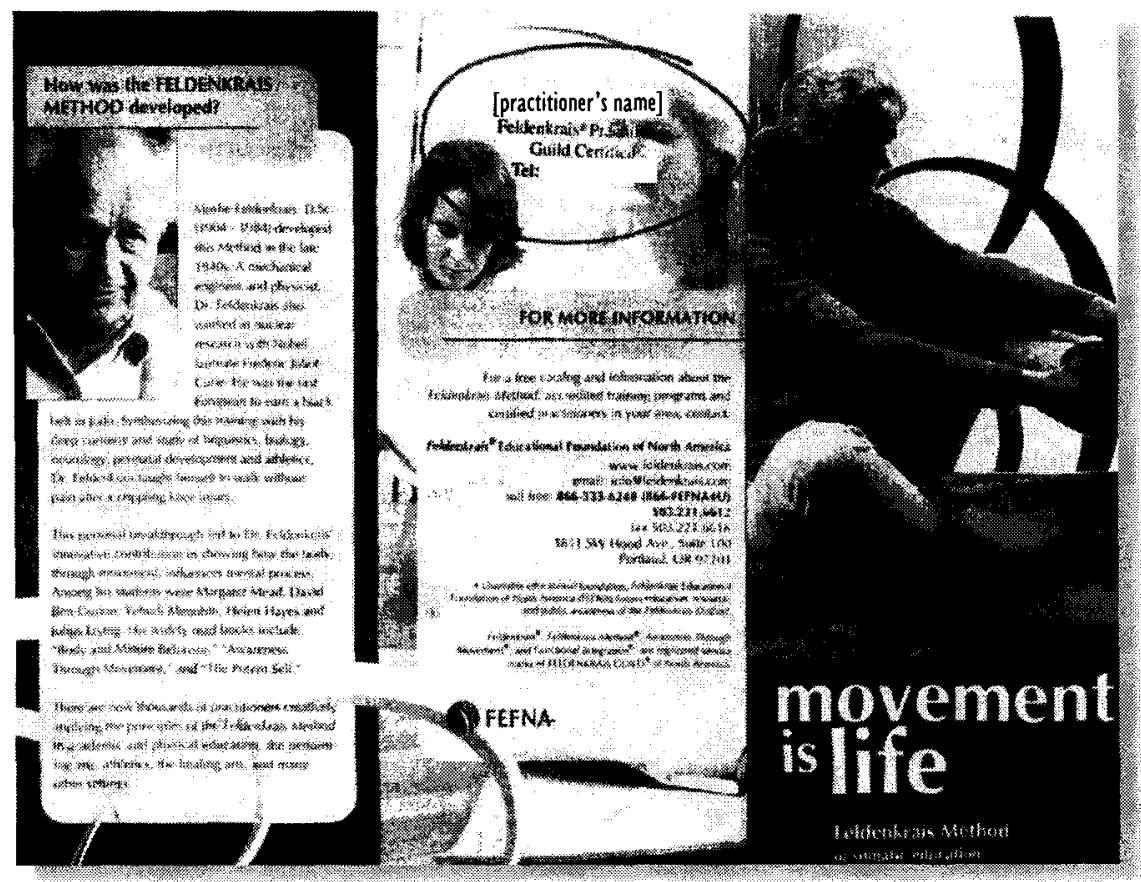

Figure 1.Text 1 (brochure).

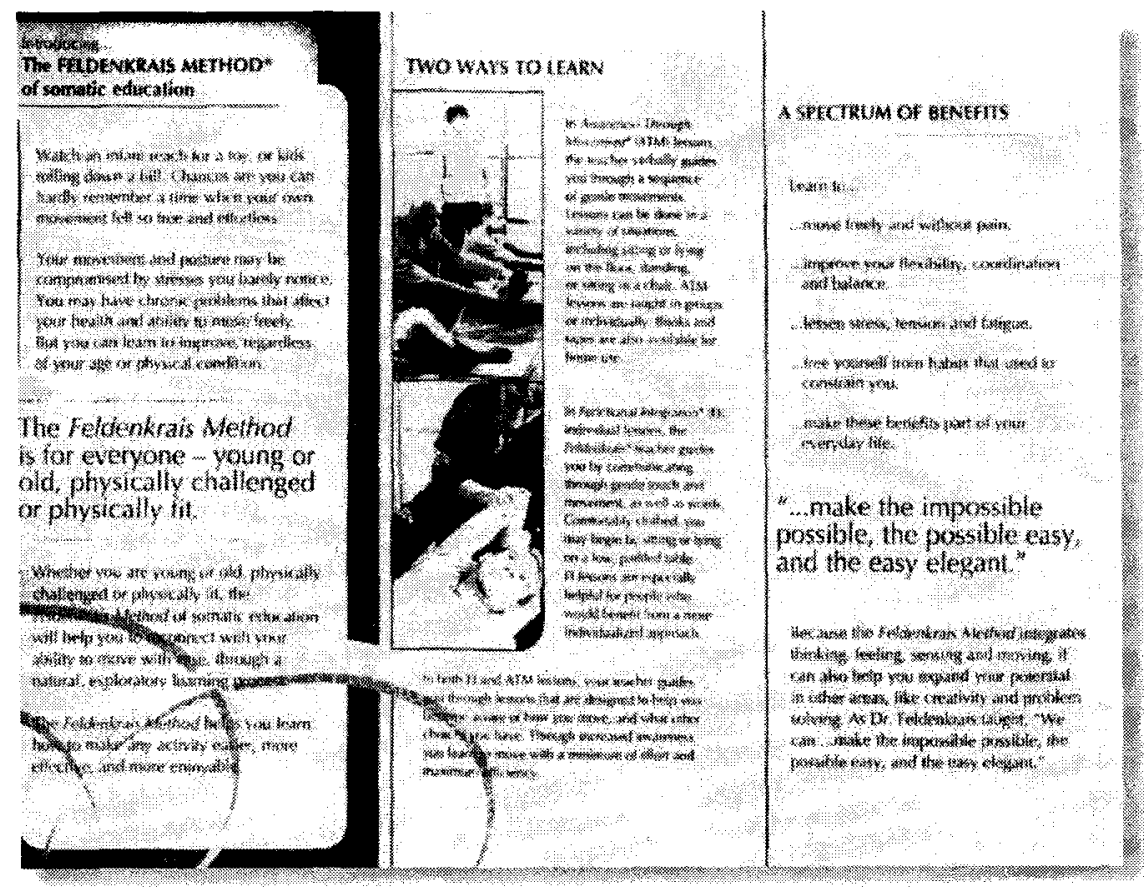




\section{Shoulder to Shoulder}

- Computer work causing stiffness?

- Sore neck or aching back?

- Posture tension?

\section{Learn how to reclaim shoulder comfort \\ with}

an

Awareness Through Movement(8)

Workshop

Feldenkrais Method®

\section{Sunday February $3^{\text {rd }} 1 \mathrm{pm} \sim 4: 30 \mathrm{pm}$ \\ 380 Springfield Rd. \\ Rockcliffe Community Hall}

Cost $\$ 48.00$

Free Parking

Information [Practitioner's Name]

Guild Certified Feldenkrais Practitioner(\$)

Awareness Through Movemento Instructor Functional Iategration@ Teacher

Figure 2. Text 2 (workshop poster).

The following section discusses our findings based on the analysis of persuasive effectiveness of the sample promotional materials. The information is presented in the form of responses to the questions that guided our analysis.

1. What are the needs of the Feldenkrais Guild? What motivated the production and distribution of the promotional materials?

According to Paré and Smart (1994), the composing process begins with an initiating event (p. 151). The Feldenkrais Method brochure and workshop poster were 
produced with the purpose of responding to an apparent need to popularize this alternative method of exercise and rehabilitation and to attract new clients. One of the Method practitioners articulated this goal in the interview as follows: "I would love to have some way of encouraging people to let them know how marvelous Feldenkrais is compared to massage ... basically I want more people to know about this. "A secondary, but equally important purpose for the production of the promotional materials arises from a genuine concern for the well being of others. Practitioners want to educate people about alternatives in rehabilitative health methods. In one of the practitioner's own words: "You want people to stop hurting themselves." And, of course, there is the need of the practitioners to attract clients to their workshops and classes because these activities serve as their source of income. Thus, there is a clear exigence for the production of each promotional brochure or poster.

While the same needs motivated the creation of both texts, more specific needs that differentiate the brochure from the poster should be acknowledged. Text 1 (Figure 1) serves to define the F.M., explain the two types of classes offered (Awareness Through Movement and Functional Integration), and provides some information on the Method's history. Text 2 (Fig. 2) provides the dates and location of an F.M. workshop and serves to inform and attract the public to a particular F.M. event. The understanding of the initial needs of the text's writers provides a preliminary ground for the analysis of the promotional materials. The evaluation of the texts is now possible from the perspective of whether these materials do or do not meet the Guild's and the local practitioner's intentions.

2. How can we assess the persuasive effectiveness of the promotional materials?

To assess the persuasive effectiveness of the sample of the F.M. promotional materials we analyzed the text structure, rhetorical moves, and style using the following categories:
a. Text Layout
b. Accessibility of Information
c. Implied Audience
d. Credibility

\section{a. Text layout}

The first difficulty readers are likely to encounter is that of navigating through the promotional materials due to the overall organization of the text and the accompanying illustrations.

Text 1 (Fig.1): 
A brief glance at the brochure reveals several problems with its layout. A spectrum of benefits described on the fourth panel would have served to capture a reader's attention more effectively if placed on the first or the second panel. For example, the phrase "free yourself from habits that used to constrain you; make these benefits part of your everyday life" would be more effective if placed at the beginning of the brochure as it would indicate to the readers what benefits they could expect from the F.M. classes.

The fifth panel provides a short biography of the Method's founder, Dr. Feldenkrais, along with his photograph and other information. The paragraphs following the biography include sentences with key information that is crucial for those unfamiliar with the Method. The first paragraph states, "the body, through movement, influences mental process" and the third paragraph mentions that the principles of the F.M. have been applied in performing arts, athletics, and other settings. This information would have been more effective at the beginning of the brochure where readers could easily find it.

The last page provides contact information of the local practitioner and the FEFNA. A weak point of the page is inconsistency in formatting the telephone numbers. Some numbers have a dash between the digits and others (telephone and fax) have dots as in 503.221.6616. Overall, the text layout does not provide a reader with easy access to the necessary information on the Method.

Text 2 (Fig.2):

This text advertises a specific F.M. workshop developed to help alleviate discomfort in the shoulders. The title Shoulder to Shoulder is in enlarged bold font and centered, followed by three bulleted questions that direct the reader's attention. The date, time, and location of the workshop are followed by its cost and the words "Free Parking." The name of a contact person is provided below. The entire text is centered except for the cost and free parking notice, which appear at the opposite margins of the page.

The organization of this text is visually pleasing and allows for finding and reading the information quickly. However, the questions asked at the beginning may limit the targeted audience, as they seem to address people working with computers or playing golf and tennis.

In terms of other formatting features, the words "with" and "an" are underlined, though they are not key words. A few errors in punctuation (comma missing in the date of the workshop and the tilde ${ }^{6}$ used instead of a dash in the time and in the phone number) may lead the reader to question the source and possibly the quality of the workshop.

Even though the text layout would allow readers to find necessary information quickly, the issue of the accessibility of information remains. 


\section{b. Accessibility of information}

We use the term accessibility of information to characterize how easy or difficult it is for readers, belonging to different socioeconomic groups and of varying literacy abilities, to read, understand, and recall a particular text. Making texts accessible and understandable to everyone is fundamental if the writer wants the reader to understand the meaning of the message. The F.M. promotional materials, claimed to be addressed to "anyone and everyone," contain a number of words and phrases that may make the texts harder to understand by some readers.

Brochure (Fig.1):

The complex sentence structures of the brochure may deter some readers: long noun phrases, indirect questions, adjective phrases and too much information per sentence make some of them difficult to read. Such sentences appear in the section on Dr. Feldenkrais's life story (Panel 5), for example, "a mechanical engineer and physicist, Dr. Feldenkrais also worked in nuclear research with Nobel laureate Frederic Joliot-Curie" and "Synthesizing this training with his deep curiosity and study of linguistics, biology, neurology, perinatal development and athletics, Dr. Feldenkrais taught himself to walk without pain after a crippling knee injury." For some readers, dense information packed into the beginning of a sentence can be confusing: one might wrongly assume that knowledge of linguistics, biology, neurology, perinatal development, nuclear physics, and athletics is what allowed Dr. Feldenkrais to walk normally again.

These complex sentence structures and vocabulary choices are specific to the brochure (Figure 1, Text 1). No complex sentences or difficult vocabulary items were found in the workshop poster (Figure 2, Text 2).

c. Implied audience

Although some readers may not be prepared to encounter and interpret medical terminology, the use of specialized vocabulary is a regular feature of the brochure. The very first sentence of the brochure (Fig. 1) reads "Feldenkrais Method of somatic education," while the word "somatic" is not a commonly used word, and it is neither defined nor explained. Some words that may be common to certain types of texts do not "fit" in the promotional material language that claims to address a general reader. For example, in Text 1 (Fig. 1) we find the following words in italics that may cause difficulty to the readers trying to process them: a spectrum of benefits; exploratory learning; synthesizing this training, and others.

In the same way, the texts claim to address people who are healthy, but mostly talk about those who are ill. In the brochure (Fig. 1), the first paragraph attempts to involve the reader in a conversation about good old times when moving freely was a 
natural feeling. One might assume it is directed towards the elderly. While the materials claim to target all age groups, the text and illustrations send different messages.

Illustrations included in the promotional materials could make it difficult for "anyone and everyone" to identify with them. If a picture is worth a thousand words, then the message delivered by the illustrations in the brochure is that the Feldenkrais Method is only for the middle aged and elderly whom one can observe in the pictures and photographs. The illustrations included in the brochure (Fig. 1) are not helpful in capturing the movement practices in the F.M. classes. In Text 1 (Fig. 1) the photograph on the first page does not clearly show an exercise position or a move. In addition to these problems, the grayish tones of the pictures and tense face expressions do not reflect any enjoyment on behalf of the participants. This may lead the reader to wonder if the classes in F.M. are painful or unpleasant.

From this analysis, it becomes clear that the audience for the promotional materials is not clearly defined, contrary to the written claims. Some illustrations make it difficult for anyone to identify with the gender and age of the current clients, and more importantly, with the F.M. experience in general.

\section{d. Credibility}

One way to persuade readers to inquire about or to purchase a service is by providing evidence that the service and its source are trustworthy. Evidence of an effort to supply credibility exists in both texts we have described above. In the promotional materials, credibility is conveyed through testimonials, name-dropping, contact information, and registered mark symbols.

In Text 1 (Fig. 1), the evaluation of the service is established through a testimonial and an assertion of the abundance of Method practitioners ("there are now thousands of practitioners creatively applying the principles of the Feldenkrais method") to demonstrate that the method is used widely. The name-dropping in Text 1 appears more problematic than helpful. Names of Dr. Feldenkrais' previous students are mentioned: Margaret Mead, David Ben-Gurion, Yehudi Menuhin, Helen Hayes, and Julius Erving. Unfortunately, as we have discovered through surveying our fellow students in the graduate program in Applied Language Studies, these names are unfamiliar to many. The mention of the names of current well-known public figures (e.g., Mikhail Baryshnikov, Whoopi Goldberg, Sophia Loren, Sharon Stone, Pierre Trudeau) who have used the Method would likely prove to be more captivating and effective.

3. What can we infer from the promotional materials about writers' intentions and the reading practices of potential F.M. clients?

Written texts involve individuals in different relationships with other people (Paré \& Smart, 1994). Their roles can determine the limitations and freedom to what can be 
communicated in the text, how and to whom it is communicated (p. 149). We can infer well-defined roles of writers and readers from the analysis of the F.M. brochure (Fig. 1), the workshop poster (Fig. 2), and the interview with practitioners.

Text 1 (Fig. 1):

Individuals playing at least three roles are involved in the creation and use of the information brochure (Fig. 1): the writer/editor of the promotional text who is affiliated with the Guild (the writer and the editor may be two different people) and may be a practitioner as well, the F.M. practitioners who are responsible for the distribution of the materials, and the readers who may be defined as current and/or potential F.M. clients. The relationship between the Guild brochure writer and the F.M. practitioner can be described as one in which both share the common interest of recruiting and educating potential clients. The writer decides how the message is worded and organized, while the practitioner's role is to deliver the message. From the reader's point of view, the writer and the practitioner have the same role, that of the expert and informer. The figure of the writer may be easily confused with the figure of the practitioner who distributed the promotional materials.

Text 2 (Fig. 2):

In Text 2 (Fig. 2) the writer - in this case, an F.M. practitioner - has a complex role. Part of her role is to recruit new clients and inform potential and current clientele, and at the same time, she is the contact person and also a teacher of the F.M. workshop. The relationship between the writer and the reader reflects a seller and a consumer, in which one offers and sells Method services and the other one accepts and purchases the services or rejects them. Certain features of Text 2 define the writer's position as one of expertise and ownership. The writer is an expert because she is providing the information and representing herself as the main contact person. Ownership and credibility are evidenced by a recurring registered mark symbol after the words "Feldenkrais Method."

The workshop poster (Fig. 2) includes the time, date, and location of the workshop and contact information. Any information explaining the F.M. is excluded; the name of the Method is assumed to be self-explanatory. We can conclude that the writer has imagined the reader to be someone who is already familiar with the F.M., perhaps a current client or a person who is familiar with or has heard of the Method; thus, unwittingly, potential clients unfamiliar with F.M. may be excluded.

4. Reading Practices: How do the readers approach a text? How do they negotiate through the text? How do they understand it? What do they do with the knowledge they construct? 
From the interview with the F.M. practitioners and from the samples of the promotional materials analyzed, we can only infer the reading practices of those who read these materials. We can assert from the interview with the practitioners that some past readers are chiropractors, massage therapists, clients of health practitioners, and the general public. As for Text 1 (Fig. 1), we may infer that the readers presumably preview the text and skim it for any information of interest. Those who are given the promotional literature by a doctor or other healthcare provider may look at the text from a specific point of view, as the material recommended by a health practitioner acquires more validity and significance. If it is read in a setting that is irrelevant to medical or physical activities, it may attract interest of only those who have certain physical problems or who already know about the Method.

Text 2 (Fig. 2) may be approached a little differently. It is more likely to be posted in public places, such as community centers, where a reader would want to quickly read through it to learn what is being offered. If the reader is someone who already knows about the Method, s/he may look for specific information only, such as the date and the time of the workshop. For those unfamiliar with the F.M., well-organized (layout, vocabulary, sentence structure, etc.) and effectively illustrated texts may become of interest.

The following sub-section presents sub-study 2, the analysis of the interviews with representatives of the current F.M. clientele and potential clients. The analysis demonstrates how the readers approach the promotional materials, navigate them, and understand them. It also indicates what the readers do with the knowledge they construct while engaging with the promotional texts.

\section{Sub-study 2: Interviews with Current and Potential Feldenkrais Method Clients}

We present our findings according to the three distinct groups of the study participants: current F.M. clients, non-clients, and practitioners. This section of the article ends with a comparison and contrast of the responses received from all of the groups within our research sample.

\section{Feldenkrais method clients}

Four distinct conclusions emerged from the collected data pertaining to the F.M. clients.

The clients initially became aware of the Feldenkrais Method by word of mouth. The problem that emerges from these responses is that both current clients learned about the exercise and rehabilitation program through the recommendation of other Feldenkrais members, rather than from the F.M. promotional material.

The clients had indicated that their previous experiences with other rehabilitation therapies had been unsuccessful; therefore, they were initially very skeptical about getting involved in the F.M. The obvious issue that arises from these responses is the 
reluctance of the general public to participate in the F.M. due to prior negative experiences with other rehabilitative/exercise programs. This reluctance creates a problem for the dissemination of F.M. promotional materials since negative stereotypes about the more conventional rehabilitative methods are imposed on the F.M., thus diminishing the recruitment of a new clientele.

The clients commented on a lack of substantial F.M. promotional literature. They stated that based on the available promotional texts alone, they would not have joined the program. The problem here is the apparent contradiction in the responses we received. Even though the clients suggest that there is a lack of promotional material available, they also claim that an increase in the amount of promotional material available would not necessarily lead to an increase in the number of new clients. As indicated by the clients, it would take more than just the literature alone to persuade the general public to participate in the Feldenkrais Method.

Finally, the clients strongly alluded to the existence of what they called a "Feldenkrais society" or a tight-knit, insider F.M. group consisting of long-standing clients and practitioners who all use the same language in their discussions of the F.M.: in other words, those who form a distinct discourse community (Swales, 1990). The current clients claim to be recommending the F.M. to others and agree that an outside recommendation from a known figure is necessary in order to effectively get the F.M. message out to the general public. The fundamental problem here lies in successfully getting the F.M. message from an inner "member circle" out into the public.

Feldenkrais Method non-clients

The non-clients came to this study with a history of musculoskeletal problems; none of their problems were a direct result of injury or illness, but rather were due to the nature of their work as professionals in the high-tech sector. The non-clients also came to this study with previous rehabilitation experiences they had accumulated while trying to address their musculoskeletal problems. Moreover, neither of them had the impression that their previous rehabilitation experiences were beneficial or advantageous, this in striking similarity to the F.M. clients' impressions. The nonclients had not heard of, nor had prior exposure to, the F.M. and its promotional materials. Given this brief outline of the non-client participants' backgrounds, we thought that they could be representative of ideal potential clients for the Feldenkrais Method.

The non-clients' comments on the F.M. promotional literature with which they had been presented provided first-hand insight into the effectiveness (or lack thereof) of these texts. The most striking theme seen throughout the non-clients' responses was skepticism, this due in large part to the first impression that they received from 
the promotional materials (Text 1, Fig. 1) - namely that the Feldenkrais Method could "cure" all one's problems simply by teaching one to "listen" to one's body. What followed their reading of Text 2 (Fig. 2) were comments such as, "Okay, so we're told the fee for this supposed cure before we're even sure that it would be a wise investment, both financially and physically." The issue the non-clients had with the promotional materials was that although the materials were advertising a possible cure for musculoskeletal problems, there was a lack of comprehensive substance in the texts as to what the Feldenkrais Method "was all about."

The predominant question that arose upon the non-clients' initial exposure to the promotional texts was "Yes, but what is it going to do for me?" This suggested to us that the content of the promotional material was too general, too vague for the nonclients. And more importantly, the non-clients declared that they would not choose to participate in the Feldenkrais Method based solely on the information provided in the promotional literature. Here we find another opinion consistent with that of the F.M. clients. Overall, there was a general consensus among all the research participants that the promotional literature about the F.M. was inadequate in influencing the public to participate in the F.M. as an exercise or rehabilitation program.

In response to the question in which non-clients were asked to comment on what they perceived to be the most salient features of the texts, they highlighted the following features, which we have grouped as eliciting either a positive or negative response:

1. Positive Features

- The F.M. principle of treating the problem as a whole and not just in isolation (entire body vs. specific area). Non-clients would have liked to learn more about this.

- The Feldenkrais Method's emphasis on natural rehabilitation, such as conscious learning directed to breaking "bad" habits and breathing and stretching exercises to avoid unnecessary physical stress.

2. Negative Features

- The promotional literature seemed to be "all over the place" thus giving the impression of being too soliciting (e.g. Dr. Feldenkrais' life story, the listing of prominent figures that have benefited from the program, etc.). Non-clients saw this as unnecessary and it led to the repetition of their question, "So what is it going to do for me?"

- The reader immediately learns of the cost associated with the F.M. program (Text 2, Fig.2) "before you even know if this is the right method for you in the first place." 
- The comparison of the movements of a child to those of an adult. Nonclients considered this unrealistic and insufficiently explained, and it was not seen as at all relevant to their learning about the F.M.

\section{Feldenkrais Method practitioners}

The main issue addressed in the interview was that the practitioners continually referred to the promotional materials as not being able to effectively communicate the true experience derived from an F.M. session. For example, they stated that they wanted something in the promotional literature capable of expressing the "organic components of the body" as well as "the release of tension" in order to render "greater movement" of the body. This would convey to the reader that the F.M. is unlike other rehabilitative therapies, and it would help in advocating why people ought to participate in this program. A problem arises, however, when an attempt is made to equate a sensory, experiential unit of a movement exercise with a written, lexical unit in a promotional text, since the nature of such units is profoundly different. The structure of a written lexical unit falls short of accurately describing and representing the actual physical experience. In relation to the F.M. promotional literature, the texts convey physical experience with descriptors such as "aching back," "move freely," and "enhancing gracefulness." Because of the use of these common phrases, the total sensory experience of the F.M. is not adequately simulated or conveyed.

The second issue that emerged from the interview data is that the promotional materials for the F.M. have been unsuccessfully circulated to its target audience. The practitioners mention that the F.M. brochures and other promotional documents are for everyone, yet they contend that "another brochure is not going to be read unless you already have a predilection to read about Feldenkrais." In other words, the brochures and other promotional materials about the Method are almost exclusively read only by those already familiar with the F.M.; according to the practitioners, "they are preaching to those already converted."

\section{Comparison of opinions across participant groups}

We have attempted to bring together the responses obtained from all three groups involved in this sub-study. Discrepancies in the intention of the promotional literature and its actual effect on the public have been demonstrated in the responses of all three groups of the research participants. The F.M. practitioners' statements as to what the promotional materials should, but do not altogether successfully, reflect precisely what all readers of the promotional literature desire. The key features missing from the promotional literature are the conveying of the essence of the F.M. exercise program and the concrete, personal advantages available to future clients as a result of the program. Clients and non-clients alike all emphasize the need for these two crucial factors to be present in the promotional materials if they are to support 
the public in the decision to participate in the F.M. The practitioners see the clear presentation of the essence and the concrete personal advantages of the program as a pressing need that must be addressed in the promotional literature so that the true F.M. experience may be accurately conveyed. Conveying the Method experience could potentially be a satisfactory response to the non-clients' fundamental question of "What is it going to do for me?" It would also diffuse the firm declaration of both clients and non-clients who assert that they would not participate in the Feldenkrais Method on the sole basis of its promotional materials.

An underlying issue frequently raised in relation to the content of the F.M. promotional materials was the inclusion of positive testimonials of well-known figures. The F.M. clients suspect that known figures are more influential in convincing the public, and the practitioners second this opinion. The non-clients, however, were unmoved by the prominent people listed in the promotional material of the Method (perhaps because they did not find the figures familiar and/or authoritative). The main point that arises from this observation is that the known figures named and the positive testimonials cited need to appeal to and address the target audience. Nonclients are not persuaded by the famous figures mentioned in the existing literature. Furthermore, they are utterly indifferent, if not annoyed with the frequent namedropping of unknown figures, thus making it much easier to disregard the promotional material as anything of possible interest or benefit.

Sub-study 2 allowed us to investigate the effects Texts 1 and 2 had on two groups of their potential readers: current F.M. clients and potential clients. Our findings had confirmed the findings of Sub-study 1 and allowed us to develop a series of conclusions and recommendations, which we presented in a detailed report submitted it to the F.M. practitioners, who, in turn, shared it with practitioners across the country. The conclusions and recommendations of Phase One are presented in the following section.

\section{Phase One Conclusions}

In Phase One of the project, we conducted a rhetorical analysis of the persuasive effectiveness of the F.M. promotional materials and investigated the effect of these materials on the current F.M. clients and non-clients who might benefit from F.M. classes. The textual analysis and the empirical investigations of the F.M. promotional materials revealed certain weaknesses in the way that the Method was presented and described. As demonstrated by the textual analysis, the language used in the promotional literature of the F.M. is unnecessarily complicated and often too general and ambiguous, and thus ineffective in presenting the objective of the Method. The inefficient use of language is also asserted in the Sub-study 2 participants' responses. In 
addition, the textual analysis demonstrated that readers might encounter difficulties with the text layout of the promotional literature and inevitably become disconcerted while attempting to navigate through the materials. The analysis of the persuasive effectiveness of the F.M. promotional texts revealed that the writers of these texts have assumed an audience familiar with a specific kind of terminology. Therefore, the wording used in the promotional materials may not appeal to everyone and, more importantly, does not seem to easily attract the attention of readers. The responses received from the Sub-study 2 participants conveyed their negative impressions of the texts caused by the inefficient and generalized language used, which proved incapable of sustaining a reader's attention. Promotional materials belong to a category of texts that are expected to be concrete, concise, and to the point. Our findings indicate that the F.M. promotional materials we have analyzed do not fulfill their goal.

These findings were supported by the responses from the Sub-study 2 participants who noted that their knowledge (or lack thereof) of the Feldenkrais Method was not adequate to effectively interpret the intended message of the promotional materials. The participants noted that, in their experience, information brochures did not ordinarily contain a narrative about the life of an individual. Since readers share a general notion of what belongs in an information brochure of this kind as a genre, it is not surprising that the non-clients remarked that a section found in Text 1 (Fig. 1) and entitled The Life of Moshe Feldenkrais was inappropriate for this kind of text and should have been entirely omitted. That is, the readers observed that the brochure had not met their expectations of the genre.

A salient feature that has recurred throughout our investigation is that the F.M. members can be presumed to be a specific "discourse community" (Swales, 1990). Such a community can be defined on the basis of the shared values, linguistic conventions, and behavioral norms that have become relatively fixed and standardized within that community. Such features of thinking, speaking, and behaving play a large part in determining who belongs to this community and who does not. The textual analysis and the analysis of the participants' responses have revealed that many features found within the F.M. promotional materials exclude a large number of individuals who could stand to benefit from the program. There are a number of terms, phrases, and sentences that make the promotional materials inaccessible to readers belonging to different social and occupational groups and to readers of varying literacy abilities. Essentially, one of the conclusions of Phase One is that the promotional materials have been created by the members of the F.M. discourse community for the members of that same community and as such, limit the general public from accessing the resources and the services provided by Method practitioners. 


\section{Phase One Recommendations}

We have developed a series of recommendations for the design of future promotional materials for the Feldenkrais Method. These recommendations are based on the findings of the analysis of the persuasive effectiveness of the promotional materials (Sub-study 1) and the responses provided by the Sub-study 2 participants. We believe that these recommendations, when used to create a new set of promotional texts, can facilitate public access to and spark interest in the Feldenkrais Method and broaden access to its practices.

- Define the Feldenkrais Method

A concise and non-technical definition of the Method is needed in all major promotional texts. The assumption underlying this recommendation is that a definition that can be easily explained and understood will enable readers to learn and then share their knowledge about the Method with others. Readers can then spread the message about the Method, which, in turn, can lead to an increased public interest and attract more people to the Method. This is necessary, given that our findings have demonstrated that word of mouth was the primary means by which the Feldenkrais Method gained public interest and recruited new clients.

- Target audience

It would be useful to have materials designed and developed for a specific audience. This target audience could be part of a particular social and/or professional group in the community, such as physicians, students, teachers, athletes, high-tech employees, etc. To accomplish such a task, information packages should include information and language-specific features pertinent and relevant to the specific groups.

- Improve the quality of promotional materials

The text layout, content, and pictures in the brochures and workshop posters need to be made more attractive and effective. To make the existing texts more appealing and user-friendly, we have developed the following suggestions:

- Organize the text to facilitate the readers' task; that is, restructure parts of Text 1 (Fig. 1) in an effort to eliminate any guesswork on behalf of the readers and to immediately attract their attention to the Method

- Make information accessible to readers by eliminating extended use of specialized jargon and vocabulary

- Keep sentences simple, short, and relevant to the purpose of the text

- Eliminate unnecessary details and information - when there is too much detail readers miss the "big picture" of what the writer wants them to see 
- Make all drawings and photographs inclusive and clear; for example, include those depicting people of different ages, gender, and culture. Upgrading paper quality will also help with the clarity of photographs.

- Make the Feldenkrais Method sound more credible

We suggest the following " $3 \mathrm{R}$ principle": remove, reserve and replace. For a more credible text:

- Remove the section on Dr. Feldenkrais' life story. From the reader's perspective, such information is irrelevant and, further, it distracts the reader from the main point: the Method itself.

- Reserve the extent of name-dropping found in the existing promotional materials.

- Replace the names of lesser-known figures with those more widely known. When and if name-dropping is appropriate, names of well-known figures should be used.

- Cross reference promotional materials. Refer readers to other, more substantial sources of F.M. reading material in each promotional text. All materials should provide a link to the F.M. website where readers can learn more about the history of the Method and the details of the program and can browse a more extensive and diverse list of (known and unknown) people sharing their experiences with the Feldenkrais Method.

The findings and recommendations of Phase One coupled with the Feldenkrais Method practitioners' positive response to the Phase One report motivated the continuation of this project by another group of graduate students in the winter term of 2003. Phase Two of the project is presented in the following sections.

\section{Phase Two: Implementation of Phase One Recommendations}

While Phase One of this project examined the reasons why the original F.M. promotional materials had not attracted enough attention and interest from potential clientele and revealed a number of problems in the materials, the aim of Phase Two was to develop new F.M. promotional materials for the local practitioners by focusing first on the creation of a more comprehensible text through using language accessible to the target audience and second on the development of a new layout for the promotional materials. The design of new promotional materials is based on the assumption that the effective organization and illustration of the materials is essential in attracting readers' attention and increasing the number of new clients. 
In the process of creating new promotional materials for the Feldenkrais Method, we have continued to draw on the work of Paré and Smart (1994), particularly on their definition of the four dimensions of genre (p. 147) as discussed above in the Theoretical Framework. In addition we adopt Schryer's (2000) view that genres are only "stabilized for now" (p.45). Writers of promotional materials need to be aware that the materials can influence the audience only as long as they address its current needs, and as the needs of the audience change, so should the genres of the promotional materials. RGS furthered our understanding that every written text, be it a brochure or a workshop poster, should be designed to elicit a context-specific response from readers. The development and design of the new promotional materials in Phase Two is based on these considerations.

Our participation in ATM lessons allowed us to participate in a setting specific to the F.M. practice as well as observe the social activity and the rhetorical practices of the community, which included the practitioner guiding the clients through the lesson and the clients communicating with the practitioners and each other. When sharing their knowledge of the F.M. practice with us, the practitioners claimed that these rhetorical practices had not been accurately reflected in the original promotional materials, which, along with other problems identified in Phase One of the project, resulted in the failure of the materials to attract new clientele.

The analysis of the international F.M. websites revealed weaknesses similar to the ones identified in the F.M. promotional materials in Phase One and helped us approach the process of developing new promotional materials by carefully avoiding such problems. In addition we have learned that the F.M. can be distinguished from other comparable services because it allows clients to continue learning independently. We considered this information integral to the description of the Method and have concluded that it must be included in the new promotional materials.

While collecting and analyzing promotional materials published by the F.M.competitors, we observed that health stores and pharmacies had specific areas designated for the display of promotional materials including those related to the field of physiotherapy. The use of these spaces to display the F.M. promotional materials may result in the attraction of more clients to the Method.

Procedures for the Development of the New F.M. Promotional Materials

To facilitate the process of the design of the new promotional materials, we have developed two tables that describe typical features of the genres of the new promotional materials. These tables are based on Hammerich and Harrison (2002). Hammerich and Harrison worked with designers and programmers studying how text, visuals, and graphics can affect users' understanding of a website. We have noticed that there are considerable similarities in the tasks and steps necessary for the 
Table 1 - Layout of the new F.M. promotional materials ${ }^{7}$

\begin{tabular}{|c|c|}
\hline Areas of Design & Layout \\
\hline Layout Principles & $\begin{array}{l}\text { - Maintain a clear distinction between textual and visual } \\
\text { messages in order to facilitate a reader's navigation } \\
\text { through the text. } \\
\text { - Observe efficient rhetorical organization, e.g., position } \\
\text { of the title, logos, and relevant text that attract, inform, } \\
\text { and educate clients about the Method. }\end{array}$ \\
\hline Choice of Images & $\begin{array}{l}\text { - Use one and the same distinct icon/logo in all types of } \\
\text { the promotional materials to establish identification } \\
\text { with the local F.M. community, while maintaining clear } \\
\text { links to the Guild. } \\
\text { - Use clear images (pictures and illustrations) of people } \\
\text { from different age, gender, and race groups who } \\
\text { participate in the F.M. classes. } \\
\text { - Use visual images that complement text and vice } \\
\text { versa. }\end{array}$ \\
\hline Fonts & $\begin{array}{l}\text { - Use one and the same font type and size for the F.M. } \\
\text { logo to establish a trademark for the local F.M. } \\
\text { practitioners. } \\
\text { - Use one and the same font type and size to signal } \\
\text { different sections (headings) in the text. } \\
\text { - Use one and the same font type and size for the } \\
\text { general text to achieve uniformity across promotional } \\
\text { materials. }\end{array}$ \\
\hline Lines and Spacing & $\begin{array}{l}\text { - Be consistent when using spacing to indicate new } \\
\text { sections in the text. } \\
\text { - Use extra spaces between paragraphs (sections) and } \\
\text { bullets to promote ease of the access to information. }\end{array}$ \\
\hline Choice of Colours & $\begin{array}{l}\text { - Use one and the same paper colour so that the } \\
\text { promotional materials printed on the paper of this } \\
\text { colour can be easily associated with the F.M. } \\
\text { - Be consistent in the use of colour in the printed } \\
\text { materials to provide uniformity among the different } \\
\text { types of the F.M. promotional materials. }\end{array}$ \\
\hline
\end{tabular}


development of websites and promotional materials. However, our tables, although initially informed by Hammerich and Harrison (2002), have been developed exclusively to provide grounding for the development of the new F.M. promotional materials and to describe the tasks and steps that we have taken in Phase Two of the project to create and design the new promotional materials. The resulting tables outline the step-by-step creation of the new promotional materials. We consider these tables as representing the rhetorical strategies employed in the process of the design of the new promotional materials.

Table 1 highlights the main principles applied to the development of patterns and regularities in the materials in order to enhance graphics and visuals. We believe that, because of the emphasis put on the desired visual effect, the suggested strategies help us develop a more appealing layout for the new promotional materials. By taking into account the patterns and regularities of the promotional materials revealed in Phase One of the project, we account for the exigencies of the rhetorical situation that involves the interactions between the writers of the F.M. promotional materials and their readers.

Table 2 outlines the range of tasks and steps involved in the development of the new F.M. promotional materials: that is, the regularities in the composing processes and reading practices (cf. Paré \& Smart, 1994). The table takes into account the exigencies of the rhetorical situation that involve the readers and writers of the promotional materials as well as the social factors that affect the writer/reader interaction and that, consequently, should be considered in the process of creating the new materials (as discussed in Phase One). Table 2 accounts for the need for promotional materials; that is, clients' and potential clients' possible needs and questions (as discussed in Phase One). The revision of the new promotional materials, undertaken after the meeting with the F.M. practitioners and a discussion of the drafts of the new materials, aims to import the expertise of the F.M. practitioners as to the veracity of the content of the promotional materials which we see as social action.

A set of three promotional material items was created during Phase Two of the project. Each document belongs to a different genre of promotional materials: a brochure (Fig. 3), a beginner's guide (Fig. 4), and a workshop (or open house) poster template (Fig. 5).

In a brief overview, the brochure explains what the Feldenkrais Method is, describes the two types of instruction offered, presents the origins and nature of the method, its philosophy and pedagogy, and advises on how to choose a practitioner (Feldenkrais ${ }^{\circledR}$ Guild of North America, n.d.; Feldenkrais resources, n.d.). Its purpose is to generate readers' interest and a desire to become involved with the Feldenkrais Method. The brochure aims to reach a specific audience (computer professionals, 
Table 2. Writing and editing promotional texts for the F.M. as social section ${ }^{8}$

\section{Step 1 - Research Task}

- Gathering and analyzing information about the F.M.

- Participating in and observing the F.M. practice settings.

- Analyzing content of the promotional materials produced by the F.M. competitors.

\section{Step 2 - Organization of Information in the Promotional Materials}

- Synthesizing information into logical sections and organizing the text to facilitate the readers' task.

- Ensuring content coherence and structuring information by eliminating unnecessary details.

- Being consistent in providing the Guild website address in all types of promotional materials.

\section{Step 3 - Writing and Revising the Promotional Materials}

- Anticipating and responding to the potential clients' needs and questions.

- Expressing complex medical and Feldenkrais-specific concepts in accessible language.

- Creating short, explanatory headings and titles.

- Using bullets effectively.

\section{Step 4 - Text and Visuals}

- Visualizing how text, graphics, and pictures work together.

- Selecting pictures and illustrations according to the target audience's needs.

\section{Step 5 - Editing the Promotional Materials}

- Proofreading and peer-conferencing to avoid ambiguities in the text.

- Recognizing inconsistencies in facts, names, and spelling in the existing and new materials.

- Improving flow and coherence of the text.

- Reorganizing written content for greater clarity.

\section{Step 6 - Copyediting}

- Ensuring that each level of headings is consistent in the presentation across the materials.

- Checking titles, subtitles, and bulleted sections for coherence and clarity.

- Noting inconsistencies in font styles, colours, and sizes.

\section{Step 7 - Proofreading}

- Checking text for errors, omissions, and inconsistencies missed during copyedit.

- Correcting grammar and punctuation.

- Recognizing when text lines break poorly and correcting the breaks to enhance the flow of meaning.

- Ensuring that all corrections are made properly. 


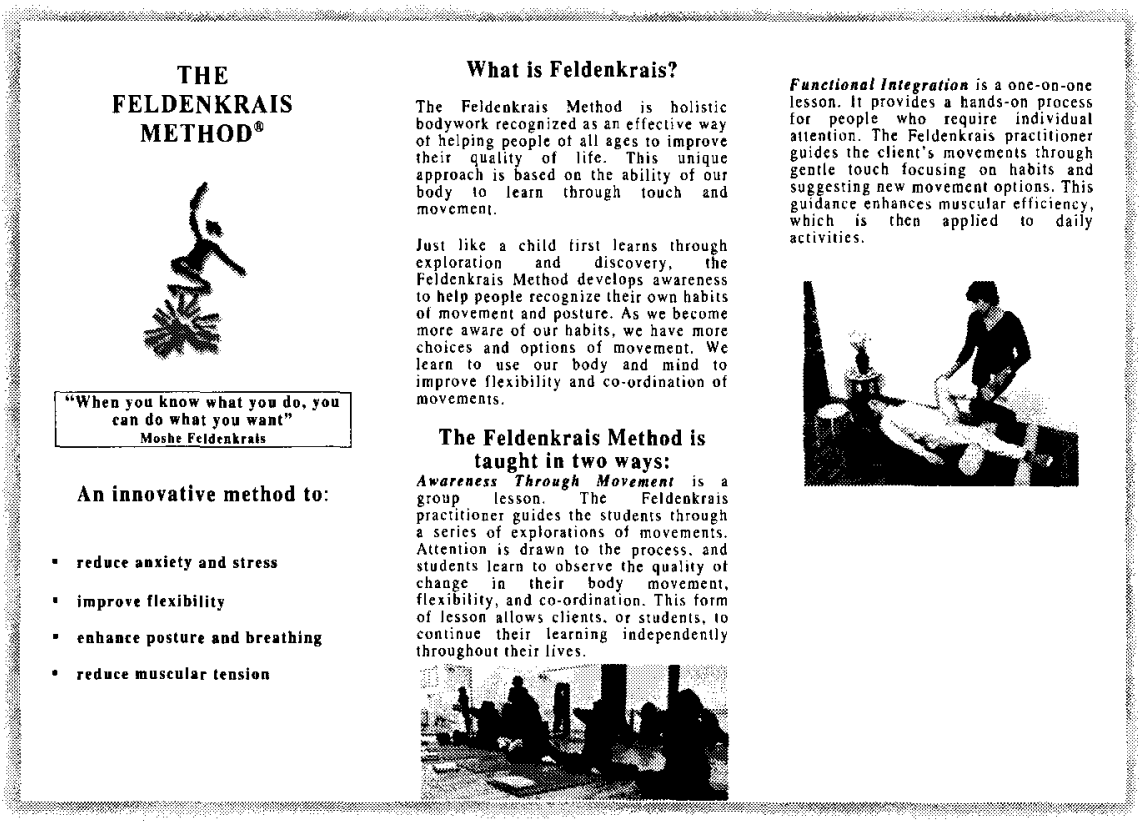

\begin{tabular}{|c|c|c|}
\hline The Feldenkrais Method & The Method and its origins: & How to choose a practitioner: \\
\hline $\begin{array}{l}\text { - Hexibility, strength, coordination, } \\
\text { balance, efficiency, breathing, } \\
\text { speech, learning, self-image, injury } \\
\text { prevention, pain raanagement, } \\
\text { recovery from surgery; in other } \\
\text { words, the quality of life. }\end{array}$ & $\begin{array}{l}\text { The Feldenkrais Method has strong } \\
\text { scientific roots. Dr. Moshe Feldenkrais } \\
\text { (1904-984) creator of the method, } \\
\text { researched huraan movements and } \\
\text { development using his knowledge in } \\
\text { engineering and physics. His rich and } \\
\text { varied background in various disciplines } \\
\text { enabled him to develop an understanding } \\
\text { of the relationship between the body and } \\
\text { mind. }\end{array}$ & $\begin{array}{l}\text { The FELDENKRAIS GLILD of North } \\
\text { America is an international } \\
\text { organization of practitioners whose } \\
\text { Professional Training Programs are } \\
\text { approved and tegulated by the North } \\
\text { American Training Accreditation Board. } \\
\text { All practitioners have completed a } \\
\text { Professional Feldenkrais Training } \\
\text { Program, and continue to develop their } \\
\text { skills through further study and training }\end{array}$ \\
\hline $\begin{array}{l}\text { Is the Feldenkrais Method } \\
\text { for me? } \\
\text { Yes. People from difterent walks } \\
\text { of life have benefited from it: }\end{array}$ & $\begin{array}{l}\text { In addition to his involvement in } \\
\text { science, he was a soccer player and a } \\
\text { judo master. A severe knee injury } \\
\text { inspired him to understand more about } \\
\text { human movement and, eventually to cure } \\
\text { himself. }\end{array}$ & $\begin{array}{l}\text { in order } 10 \text { meet yearly certification } \\
\text { requirements. There are over } 1300 \\
\text { practitioners in North America. Visit } \\
\text { our website at www.feldenkrais.com }\end{array}$ \\
\hline $\begin{array}{l}\text { - teachers, students, athletes, artists, } \\
\text { actors, musicians, dancers, martial } \\
\text { arts instructors, computer users: } \\
\text { - those with learning disabilities, } \\
\text { neurological disorders, arthritis, } \\
\text { backaches, muscle cramps, auto } \\
\text { immune diseases and physical } \\
\text { injuries. }\end{array}$ & $\begin{array}{l}\text { He was a passionate human being who } \\
\text { used all that he knew to develop a unique } \\
\text { way for pople to realize their full } \\
\text { potential. }\end{array}$ & $\begin{array}{l}\text { In the Ottawa area, you can } \\
\text { contact: }\end{array}$ \\
\hline \multicolumn{3}{|l|}{$\begin{array}{l}\text { You learn to go at your own pace and } \\
\text { comforit level. }\end{array}$} \\
\hline & 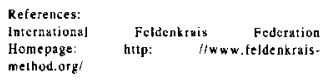 & $\begin{array}{l}\text { The terms Feldenkrais, Funcliunal Tniegration } \\
\text { and Awareness Thrnugh Movement are } \\
\text { registered marks in Canada of The } \\
\text { rELDENKRAIS GUILD' of North America }\end{array}$ \\
\hline
\end{tabular}

Figure 3. 


\section{The Feldenkrais Method}

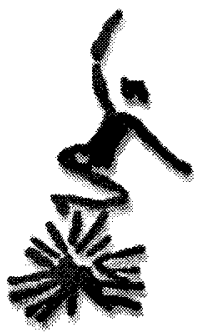

\section{Beginner's Guide}

\author{
BE FLEXIBLE
}

"When you know what you do, you can do what you want" Moshe Feldenkrais musicians, scholars, and athletes) at the same time as it tries to target people with physical injuries.

The beginner's guide explains in simple, easily accessible terms what the F.M. is and what it does. It is a more comprehensible text that provides practical information for new clients as to what they should wear, what to expect from the first lesson, how many lessons to take, and how to find a practitioner (Feldenkrais Guild of North America, n.d.). The beginner's guide aims to educate, inform, and attract a general audience to the Method in a personal and more informal way.

The aim of the poster is to advertise local activities organized by F.M. practitioners (workshops and open house events). The poster is designed to meet more current and immediate needs of practitioners, such as to inform poten-

\section{What is the FELDENRRAIS METHOD ${ }^{\circ}$ ?}

The Feldenkrais Method is a leaming process based on the ability of our body to learn through touch and movement. It helps people of all ages to use their body and mind to improve the flexibility and co-ordination of their movements.

Is the FeLdENKRais METHod for me?

Yes.

People from different lifestyles and those facing different conditions have benefited from the method. The Feldenkrais Method reaches a wide range of people of all ages and capacity as it based on such basic human experience as movement.

\section{What happens in the first lesson?}

A Feldenkrais practitioner guides you verbally to perform a sequence of movements. You learn how to feel your movements and become aware of them. More importantly, you learn what movements are beneficial for your body.

\section{What should I wear?}

Comfortable clothes, you may find yourself lying on a mat or sitting in a chair.

\section{How many lessons do I need?}

It is up to the individual. With the Feldenkrais Method, you learn to go at your own pace and comfort level. The method does not make you dependent on the practitioner. You are encouraged to learn for yourself so that you can practice the method independently

\section{Should I choose Awareness Through Movement} (ATM group classes or private Functional Integration" $(F D$ lessons?

Awareness Through Movement is a group learning process. The Feldenkrais practitioner instructs the students to follow a series of movements. This form of lessons allow you to continue your learning throughout your life.

Functional Integration consists of one-on-one lessons. They are designed for people who require individual attention. The Feldenkrais practitioner guides the client $s$ movements through gentle touch focusing on habits and suggesting new movement options. This form of instruction is particularly useful for overcoming problems caused by stress, accidents or illnesses.

Both ways of instruction are beneficial for people who want to feel and perform better both physically and mentally.

\section{How do I find a practitioner?}

You can use the FELDENKRAIS METHOD website: www.feldenkaris.com to find a qualified Feldenkrais practitioner in Canada near you. You can also email your questions using the online directory of the Feldenkrais practitioners. Some of the Awareness Through Movement classes are also available online.

\section{Figure 4.}




\section{T面e

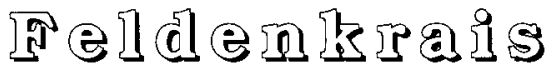

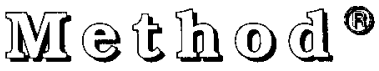

Awareness Through Movement (ATM) ${ }^{\circledR}$

\section{WORKSHOP}

Help Your Back

Regain your comfort and flexibility

with

LISA WOOLNOUGH

Guild Certified Feldenkrais Practitioner ${ }^{\oplus}$

Sunday, April $27^{\text {th }} 2003$

Rockcliffe Park Community Hall

380 Springfield Rd

For information: 744-0868

Cost: $\$ 40.00$

\section{Figure 5.}

tial workshop participants and clients about dates, locations, and cost of scheduled events. It serves to inform a general audience about the Method and to attract a broader public interest to it. 


\section{Design of the New Promotional Materials}

The overall layout (i.e. the combination of text and complementing visuals) of the new promotional materials has been developed to be visually pleasing and to allow the readers of the promotional materials to locate and read the information quickly. The uniformity in the layout of the three types of promotional materials (the brochure, beginner's guide, and workshop poster) has been achieved primarily through the use of the uniform title, logo, and paper colour in all of the newly created promotional materials. Below we describe the similarities in structure, rhetorical moves, and style of the promotional materials, using the following categories: (a) Layout (b) Writing and Editing as Social Action (c) Audience (d) Credibility, and (e) Competitors.

\section{a. Layout}

Visuals (illustration/pictures) play a very important role in the design of promotional materials. In an attempt to achieve a clear layout in all three documents, we developed a few design strategies for the brochure (Fig.3), beginner's guide (Fig.4), and workshop poster (Fig.5). The brochure aims at a specific social/professional target audience (i.e., potential F.M. clients who may experience repeated musculoskeletal problems caused by their work: computer users, scholars, athletes, artists, actors, musicians, and others); it is double-sided, folded twice, and divided into six panels. The beginner's guide aims to attract the general audience to the Method; it is doublesided, folded once, and divided into three panels. The workshop poster aims to inform the general public about workshops and open house events. Below we describe common features in the design of the layout that allowed us to achieve uniform rhetorical organization in the three samples of the new F.M. promotional materials.

- Font Type and Lines and Spacing: Consistency in the font choice, spacing, and the use of center spacing to indicate new sections in the text and provide balance across panels is the cornerstone of the design of the promotional materials as it creates uniformity throughout all materials. The use of bold fonts and bullets promotes easy access to information by providing cues to readers and allowing them to quickly find what they are looking for.

- Details of front cover: The following similarities have been created to promote the uniformity of the image and design to create a recognizable "identity" in all three types of the promotional materials:

(1) The position of the title (The Feldenkrais Method) and logo at the top (headline) of the cover to create one and the same image so readers can easily recognize it and associate it with the F.M. 
(2) The use of Dr. Feldenkrais' thought provoking quotation on the cover of the brochure and beginner's guide to create identification of the method with its founder and, consequently, increase the Method's credibility. The cover of the brochure also informs the reader in bulleted sentences about the four main benefits of the Method.

- Text Layout and Illustrations: Clear distinctions have been maintained between textual and visual messages facilitating the reader's navigation through the new promotional materials. The illustrations selected are aimed at the general audience by showing an image of each of the two types of the F.M. lessons, Awareness Through Movement and Functional Integration. The text explains how each of the lesson types works, their differences, and benefits. The text and the illustrations complement each other, thus reducing possibilities of the reader wondering what each type of the lesson "is about."

- Choice of Colours: The same paper colour (warm and soothing "tan" colour) has been used for all three types of the new promotional materials. Consistent use of the same paper for printed material provides uniformity among the different types of promotional materials.

- Space for Practitioner Information: On the last page of the brochure and beginner's guide, a space has been created where practitioners can affix their business cards to facilitate contact with new clients. On this page the reader can also find the website address (URL) and accreditation and licensing requirements to certify F.M. practitioners.

\section{b. Writing and editing as social action}

We have ensured content coherence, structuring of information in uniform logical ways and, most importantly, the use of accessible and understandable language by avoiding technical or specialized language in the new promotional materials. We have also made a decision to describe the F.M. in the brochure (Fig.3) and beginner's guide (Fig.4) by using language that clearly communicates to a lay audience. The main goal of the material design was to anticipate and respond to the clients' and potential clients' needs and questions (as analyzed in Phase One). While the need to promote the Method and attract more clients motivated the creation of both the brochure and beginner's guide, each of them had an individual function and target audience.

\section{c. Audience}

In the development of promotional materials the addressed audience always plays an important role. We have focussed our attention on the use of accessible language. 
One way to achieve this is to express complex technical and medical terminology in a simple and clear manner. For this purpose, it is most important to first define the target audience for the brochure (Fig.3), beginner's guide (Fig. 4), and workshop poster (Fig. 5).

As mentioned above, the brochure is a text addressing a specific social and/or professional audience of potential F.M. clients such as computer users, scholars, athletes, actors, musicians. The beginner's guide is a more personal and informal text that addresses those who are prepared to start F.M. classes. The workshop poster is designed to attract clients to the F.M. activities (workshops and open-house events). Essentially, the new promotional materials have been created not for the F.M. discourse community (i.e. practitioners and already recruited clients) but for the oftenexternal target audience: potential clients.

\section{d. Credibility}

The recommendations from Phase One of the project indicated that (1) references to the way Dr. Feldenkrais developed the Method and how he himself benefited from the method and (2) the mention of easily recognizable social figures as clients of the F.M. add to the credibility of the promotional materials. As well, the electronic address (URL) of the Guild website, a practitioner's business card, and a reference to the rigorous licensing procedure and requirements applied to all F.M. practitioners add to the trustworthiness of the Method.

\section{e. Circulation and distribution of the F.M. promotional materials}

We suggest that to reach a larger audience, circulation and distribution of F.M. promotional materials should be expanded to pharmacies, health stores, medical clinics, government and corporations, university departments, gyms, dance schools, and other locations where people interested in improving their health and ease of movement may see them. In addition, not only practitioners but also clients already enrolled in the F.M. classes can help in the distribution of copies of the new promotional materials.

\section{Phase Two Conclusions}

In summary, in Phase Two of the project we implemented the findings and recommendations provided in Phase One through the development of a new set of F.M. promotional materials. We approached the development and design of the new promotional materials by carefully considering and designing recognizable textual and visual features that reflect the social roles, composing processes, and reading practices (Paré \& Smart, 1994) of the parties involved in the writing and reading of each type of the promotional materials. The main principles applied to the development and design of the new F.M. promotional materials were: 
(a) creating a uniform layout of the F.M. promotional materials, which combines text and complementing visuals

(b) ensuring content coherence throughout each document and across the documents

(c) structuring information in uniformly logical ways through the consistent organization of information in different information blocks and, in particular, through using simple language free of technical and medical terminology in all three types of promotional materials

(d) selecting and adequately communicating information to the target audiences in each type of promotional material

(f) researching strategic ways to circulate and distribute promotional materials efficiently.

\section{Knowledge Sharing: The Approval of New Promotional Materials}

As the process of developing and designing new promotional materials for the F.M. reached its final stage, we met with local F.M. practitioners and presented the newly created materials for approval by senior F.M. practitioners and a representative of the Guild. In our presentation, we first briefly informed the practitioners about the promotional materials currently used by their competitors (i.e., the Alexander Technique; see Rickover \& Rickover, n. d.) and how the competition strategically markets its services. Second, we presented the newly developed promotional materials for the F.M., focusing mainly on: (a) the reasons for the creation of three types of promotional materials that represent three distinct genres: a brochure, a beginner's guide, and a workshop poster; (b) the overall organization of the visual layout and illustrations of the promotional materials developed to be pleasing and appealing to the readers, both familiar and unfamiliar with the Method; (c) the use of simplified language (word and sentence structure choices) to explain what the method is and what it does, in order to enhance the readability of the new materials; and (d) the position of the proposed new F.M. logo at the top of the front page of each promotional document and the use of the same font, logo, and paper colour across all three types of the new promotional materials to achieve uniformity.

The practitioners shared their knowledge of F.M. linguistic practices by clarifying the use of some terms and registered mark symbols and supplying us with some information about Dr. Feldenkrais. We incorporated this feedback into final drafts of the new promotional materials, and the local F.M. practitioners subsequently approved the three types of new promotional materials. To finalize the project, we submitted to the local F.M. practitioners a report accompanied by a CD with the new promotional materials along with their printed versions. 


\section{Overall Project Conclusions and Recommendations: Between "Worlds Apart"}

The project discussed in this article was designed in response to a request from local F.M. practitioners to analyze causes of the ineffectiveness of the promotional materials they were using at the time. The project was completed by several groups of students enrolled in a master's level course on academic and workplace genres in two consecutive years, 2002 and 2003. The goal of introducing such a project to an academic classroom was to provide students with an opportunity to enter the space between "worlds apart," or, in other words, to allow productive knowledge sharing between the F.M. discourse community and the students.

The project described in this article allowed us to apply the concepts developed within the RGS framework to the analysis of the persuasive effectiveness of the F.M. promotional materials and, subsequently, to design a new set of promotional materials. By bringing their concerns about the F.M. promotional materials to the academic classroom, the F.M. practitioners invited us to step outside of the class and enter the world of F.M. practice. Thus, we were given the opportunity to carry the knowledge acquired in the classroom into the workplace context. We conducted fieldwork that included interviewing practitioners, clients, and non-clients, participating in the F.M classes and workshops, and visiting F.M. international websites. RGS provided the theoretical background for the project by allowing us to view the texts and the contexts in which they were created as inseparable. The fieldwork alone would not have been enough had we not applied theory to analyze and evaluate the rhetorical situation of F.M. practice; nor would the textual analysis be sufficient (or even possible) had we not immersed ourselves in the world of the Feldenkrais Method.

Throughout the project there has been ongoing knowledge sharing among groups of students and F.M. practitioners. Method practitioners generously shared with us knowledge of the F.M. discourse community through a variety of promotional materials, classes we attended, interviews, and discussions of our work. We, in turn, shared with them our academic knowledge through the production of reports, presentations, and the designed sample set of new promotional materials.

As Dias et al. (1999) observe, in the academic context, students are mostly expected to demonstrate in their writing what they have learned, whereas writing in the workplace is often used for the completion of particular tasks. This project helped us understand that sharing knowledge in the space between the worlds of academia and workplace may benefit both worlds. On one hand, we benefited through the opportunity to apply our theoretical knowledge while having entered the workplace context of F.M. practice; on the other hand, the F.M. practitioners obtained a set of promotional materials tailored to their needs and the needs of their potential clients and 
understood why and how these materials were designed. Further research is needed to evaluate the success of these new promotional materials.

We agree with Hunt (2002) who believes that "it's crucially important for students to become 'better' (in the broadest conceivable sense of that word) writers ... because it is through writing ... that we can participate effectively in almost any sophisticated intellectual activity or society" (p. 145). Our project is one of the recent continuous efforts of some university instructors to provide students with the opportunity to enter the space between "worlds apart," between academic and workplace communication practices. We would like to suggest that academic/workplace projects of this sort should be more often integrated into academic courses so that students can experience workplace contexts from within and adapt their academic knowledge to these contexts and apply it appropriately. The "worlds apart" (Dias et al., 1999) may not be so far apart from each other if we make an effort to enter the space between them and turn it into a working space.

In addition, longitudinal projects of this sort provide students who take the same course in subsequent years with an opportunity to enter into a productive dialogue with previous generations of students through building upon their term papers, thus forming a chain of responsive written utterances (cf. Bakhtin, 1986). In other words, such projects allow students to experience collaboration not only with their classmates but also with previous generations of students. This experience promises to help move classroom assignments further into the space between "worlds apart."

\section{Notes}

1 We are grateful to the anonymous reviewer for the pointed comments on an earlier version of this article.

2 Rhetorical Genre Studies is a term coined by Freedman (1999, 2001, 2003a, 2003b). RGS is also known as North American genre theory (Freedman \& Medway, 1994a, 1994b).

3 FEFNA is "a charitable educational foundation ... [that] fosters education, research, and public awareness of the Feldenkrais Method" (Feldenkrais ${ }^{\circledR}$ Education Foundation of North America, n.d.). FGNA "is a nonprofit ... professional organization concerned with increasing public awareness of the Feldenkrais Method ..., the certification and continuing education of practitioners, the protection of the quality of the Feldenkrais work, and research in the Method's effectiveness" (Feldenkrais ${ }^{\circledR}$ Guild of North America, n. d.). 
4 The F.M. brochure analyzed in this project was discontinued by the FEFNA in 2003 when a new version of the brochure was produced. The brochure had been produced by FEFNA and distributed free of charge among the Guild practitioners, who, in turn, distributed it among the Method clients. Permission to use the brochure was obtained from FEFNA.

5 The workshop poster was produced by a local F.M. practitioner who was offering the workshop. Permission to use the poster was obtained from the practitioner.

6 Tilde is the mark used to indicate negation in logic and the geometric relation is similar to' in mathematics (Merriam-Webster dictionary, 1998, p. 1932).

7 The table is based on design tips provided in Hammerich and Harrison (2002, pp. 165-166).

8 The table is based on Hammerich and Harrison (2002, pp. 26-28).

9 The highlighted question remains the same in both questionnaires.

10 The highlighted question remains the same in both questionnaires.

\section{REFERENCES}

Artemeva, N. (2004). Key concepts in rhetorical genre studies: An overview. Technostyle, 20(1), 3-38

The Australian Feldenkrais Guild Inc. (n.d.). Welcome to the website of the Australian Feldenkrais Guild Inc. Retrieved January 8, 2004, from http:// www.feldenkrais.org.au/index.html

Bakhtin, M. M. (1986). The problem of speech genres. In C. Emerson \& M. Holquist (Eds.), V. W. McGee (Trans.), Speech genres and other late essays (pp. 60-102). Austin, TX: University of Texas Press.

Bawarshi, A. (2000). The genre function. College English, 62 (3), 335-360.

Bitzer, L.F. (1968). The rhetorical situation. Philosophy and Rhetoric, 1, 1-14.

Coe, R. M., Lingard, L., \& Teslenko, T. (Eds.). The rhetoric and ideology of genre: Strategies for stability and change. Cresskill, NJ: Hampton Press.

Dias, P., Freedman, A., Medway, P., \& Paré, A. (1999). Worlds apart: Acting and writing in academic and workplace contexts. Mahwah, NJ: Lawrence Erlbaum Associates. 
Dias, P., \& Paré, A. (Eds.). (2000). Transitions: Writing in academic and workplace settings. Cresskill, NJ: Hampton.

Ede, L., \& Lunsford, A. (1992). Singular text/plural authors: Perspectives on collaborative writing. Carbondale \& Edwardsville: Southern Illinois University Press.

Feldenkrais ${ }^{\circledR}$ Educational Foundation of North America. (n.d.). What the Feldenkrais Method is and what it does. Retrieved January 5, 2004, from http:// www.feldenkrais.com/standards/index.html\#what

Feldenkrais resources. (n.d.). Background information: Feldenkrais ${ }^{\circledR}$ Method. Retrieved January 8, 2004, from http://www.feldenkraisresources.com/

Feldenkrais ${ }^{\circledR}$ Guild of North America. (n.d.). About FGNA. Retrieved April 23, 2005, from http://www.feldenkraisguild.com/about/aboutfgna.html

Freadman, A. (1994). Anyone for tennis? In A. Freedman \& P. Medway (Eds.), Genre and the new rhetoric (pp. 43-66). London: Taylor and Francis. (Original work published in 1987).

Freedman, A. (1999). Beyond the text: Towards understanding the teaching and learning of genres. TESOL Quarterly, 33 (4), 764-767.

Freedman, A. (2001). Catching the wave: Rhetorical genre studies in 2001. Paper presented at the International, Interdisciplinary Conference Genre 2001: Genres and Discourses in Education, Work and Cultural Life: Encounters of Academic Disciplines on Theories and Practices, Oslo University College, Oslo, Norway.

Freedman, A. (2003a). Interactions between theory and research: RGS and a study of students and professionals working "in computers." Carleton Papers in Applied Language Studies, $X X, 39-52$.

Freedman, A. (2003b). Pushing the envelope: Expanding the model of RGS theory students and professionals working "in computers." Carleton Papers in Applied Language Studies, $X X, 53-68$.

Freedman, A., \& Medway, P. (Eds.). (1994a). Genre and the new rhetoric. London: Taylor \& Francis.

Freedman, A., \& Medway, P. (1994b). Learning and teaching genre. Portsmouth, NH: Boynton/Cook.

Glaser, B., \& Strauss, A. (1967). The discovery of grounded theory: Strategies for qualitative research. Chicago: Aldine. 
Hammerich, I., \& Harrison, C. (2002). Developing online content: The principles of writing and editing for the web. Hoboken, NJ: John Wiley \& Sons.

Hunt, R. (2001, Autumn). Between planets: What's between the worlds of worlds apart. Inkshed, 19(2). Retrieved October 27, 2002, from http:// www.stu.ca.inkshed/nlettao1/huntrev.htm.

Hunt, R. (2002). [Review of the book Worlds apart. Acting and writing in academic and workplace contexts]. Technostyle, 18 (1), 142-146.

Miller, C. (1994). Genre as social action. In A. Freedman and P. Medway (Eds.), Genre and the new rhetoric (pp. 23-42). London: Taylor \& Francis.

New Zealand Feldenkrais ${ }^{\circledR}$ Guild Inc.(n.d.). What is the Feldenkrais Method? Retrieved January 8, 2004 from http://www.feldenkrais.org.nz/

Odell, L., \& Goswami, D. (1982). Writing in non-academic setting. Research in the Teaching of English, 16, 201-223.

Paré, A., \& Smart, G. (1994). Observing genres in action: Towards a research methodology. In A. Freedman \& P. Medway (Eds.), Genre and the new rhetoric (pp. 146-154). London and Bristol, PA: Taylor \& Francis.

Schryer, C. F. (2000). Walking a fine line: Writing negative letters in an insurance company. Journal of Business and Technical Communication, 14, 445-497.

Schryer, C. F. (2002). Genre and power: A chronotopic analysis. In R. Coe, L. Lingard, \& T. Teslenko (Eds.), The rhetoric and ideology of genre (pp. 73-102). Cresskill, NJ: Hampton Press.

Spilka, R. (1993). Writing in the workplace. Illinois: Southern Illinois University Press.

Swales, J. (1990). Genre analysis: English in academic and research settings. Cambridge: Cambridge University Press.

Rickover, R., \& Rickover, A. (n.d.). The complete guide to the Alexander technique. Retrieved January 8, 2004 from http://www.alexandertechnique.com/

Winsor, D. A.(1996). Writing like an engineer: A rhetorical education. Hillsdale, NY: LEA. 


\section{APPENDICES}

\section{Appendix $A$}

FELDENKRAIS METHOD CLIENT QUESTIONNAIRE

\section{Question 1}

How did you become aware of the Feldenkrais Method? Please identify the source, and elaborate on the circumstances whereby you came to learn about the organization (For example: a physician referred me; I heard about it from a neighbour; I saw a brochure or flyer about it; etc...)

\section{Question 2}

Briefly describe your experience with the Feldenkrais Method (i.e. duration, frequency of attendance). Where do you see yourself in what you understand to be complete application of the Method (i.e. novice, intermediate or expert)? How did you get to this level of achievement (i.e. attending 'Awareness Through Movement' classes, attending 'Functional Integration' classes, or both)?

\section{Question $3^{9}$}

Here are several examples of the promotional literature published by the Feldenkrais Education Foundation of North America (see pages attached). Please review them in relation to the initial appeal they have on you (e.g. aesthetics, clarity, etc...), the information provided, and the overall message they convey. Is this the sort of thing that would lead you to participate in the services rendered by the Feldenkrais Method?

\section{Question 4}

In terms of the benefits derived from the Feldenkrais Method to date, would you recommend this program to anyone else? Please elaborate on the message you would convey, considering such factors as the value obtained from the cost incurred, warm and caring environment (i.e. staff, facilities, etc...), and the understanding of one's own body movement. 


\section{Appendix B}

\section{FELDENKRAIS METHOD NON-CLIENT QUESTIONNAIRE}

\section{Question 1}

Do you have a history of musculoskeletal problems, such as back pain, neck pain, knee pain, etc...? If so, have you sought some kind of rehabilitation or intervention for it in the past? Please describe your experience.

\section{Question $2^{10}$}

Here are several examples of the promotional literature published by the Feldenkrais Education Foundation of North America (see pages attached). Please review them in relation to the initial appeal the have on you (e.g. aesthetics, clarity, etc...), the information provided, and the overall message they convey. Is this the sort of thing that would lead you to participate in the services rendered by the Feldenkrais Method?

\section{Question 3}

Have you ever encountered promotional material for the Feldenkrais Method elsewhere? Or, have you learned of it via alternate sources other than the promotional literature?

\section{Question 4}

In your opinion, what are the most outstanding features (positive and negative) of these promotional materials? Briefly describe your reasoning behind the choices you have made. 